\title{
IMPLEMENTASI ALGORITMA FUZZY C - MEANS CLUSTERING DAN SIMPLE ADDITIVE WEIGHTING DALAM PEMBERIAN BANTUAN PROGRAM PENINGKATAN KUALITAS KAWASAN PERMUKIMAN (Studi Kasus : Kelurahan/RT se-Kota Bengkulu)
}

\author{
Robbie Shugara ${ }^{1}$ Ernawati $^{2}$, Desi Andreswari ${ }^{3}$ \\ 1,2,3 Program Studi Teknik Infomatika, Fakultas Teknik, Universitas Bengkulu. \\ Jl. WR. Supratman Kandang Limun Bengkulu 38371A INDONESIA \\ (telp: 0736-341022; fax: 0736-341022) \\ ${ }^{1}$ g1a012038@gmail.com \\ 2ernawati@unib.ac.id \\ 3andreswari@unib.ac.id
}

\begin{abstract}
Abstrak : Permasalahan kemiskinan di Indonesia sudah sangat mendesak untuk ditangani, khususnya pada wilayah perkotaan. Kementrian PUPR menyatakan salah satu kondisi fisik masyarakat miskin adalah tidak memiliki akses sarana dan prasarana dasar lingkungan yang memadai dengan kualitas permukiman yang jauh di bawah standar kelayakan. Untuk mengatasi permasalahan tersebut, pemerintah membentuk Program Peningkatan Kualitas Kawasan Permukiman (P2KKP) dengan harapan apabila kualitas kawasan permukiman dapat ditingkatkan maka masalah kemiskinan juga dapat terselesaikan. Di Kota Bengkulu, P2KKP mengelola data 14 indikator kondisi permukiman dari 1.183 RT yang tergabung dalam 67 Kelurahan dan 9 Kecamatan. 14 indikator tersebut dijadikan acuan untuk melakukan pengelompokkan RT berdasarkan kondisi permukimannya kemudian malakukan perangkingan untuk mengetahui RT-RT mana saja yang layak untuk diberikan bantuan. Dalam penelitian ini, dibangun sebuah sistem berbasis website yang dapat membantu proses penginputan data kondisi permukiman, melakukan pengelompokkan dan perangkingan serta publikasi informasi kepada masyarakat. Sistem ini akan mengimplementasikan algoritma fuzzy c-means clustering untuk proses pengelompokkan dan simple additive weighting untuk proses perangkingan
\end{abstract}

Kata kunci: Permasalahan Kemiskinan, P2KKP Kota Bengkulu, website, fuzzy c-means clustering, simple additive weighting, kluster, rangking.

\begin{abstract}
The poverty problem in Indonesia is very urgent to be addressed, especially in urban areas. To overcome these problems, the government established the Settlement Areas Quality Improvement Program (P2KKP) with the expectation if the quality of settlement areas can be improved, the poverty problem can be resolved. In the Bengkulu city, P2KKP manage the 14 indicators data of the settlements condition in 1.183 Neighborhood Association (RT) incorporated into 67 villages and 9 sub-districts. These 14 indicators are used as a reference for grouping the $R T$ based on the settlements conditions then arranged by ranking to know whose RT to determine which ones are eligible for assistance/relief. In this research, built a webbased system that can help the process of
\end{abstract}

inputting data of the settlements condition, grouping and arranging based on the ranking as well as publication of information to the public. This system will implement the fuzzy c-means clustering algorithm to the process of grouping and simple additive weighting for the process of arranging the data based on ranking. The system will classify the entire $R T$ into three clusters. Furthermore, each cluster will be done the process of ranking by comparing the indicators value of each RT therein to the highest indicator in the same cluster. Thus we will get a list of the order RT are eligible for assistance/relief in every cluster. The final step is to determine the amount of RT to be given assistance. The system will choose the $R T$ with the highest ranking on any clusters with a proportionate amount, equal or as 
Jurnal Pseudocode, Volume III Nomor 2, September 2016, ISSN 2355-5920

needed P2KKP team. Clustering and ranking process will be immediately published automatically into the website so that it can be seen by the public.

Keywords: Poverty Problem, P2KKP Bengkulu city, website, fuzzy c-means clustering, simple additive weighting, clusters, rankings.

\section{PENDAHULUAN}

\section{A. Latar Belakang}

Permasalahan kemiskinan di Indonesia sudah sangat mendesak untuk ditangani, khususnya pada wilayah perkotaan. Menurut Kementrian Pekerjaan Umum dan Perumahan Rakyat, salah satu dari kondisi fisik masyarakat miskin adalah tidak memiliki akses sarana dan prasarana dasar lingkungan yang memadai, dengan kualitas permukiman yang jauh dibawah standar kelayakan [1]. Oleh karena itu pemerintah membentuk Program Peningkatan Kualitas Kawasan Permukiman (P2KKP) dengan harapan masalah kemiskinan ini dapat teratasi apabila masyarakat tersebut diberikan edukasi dan pelatihan untuk meningkatkan memperbaiki pola hidup dan meningkatkan pendapatannya secara mandiri.

P2KKP di Kota Bengkulu diposisikan sebagai konsultan oleh Dinas Pekerjaan Umum (PU) Kota Bengkulu. Hal ini karena adanya korelasi yang sangat tinggi antara masalah kemiskinan dan kualitas permukiman di wilayah perkotaan. Oleh karena itu P2KKP setiap tahunnya mengumpulkan data-data wilayah permukiman pada 1183 RT yang tersebar dalam 67 Kelurahan se-Kota Bengkulu. Data data tersebut akan diolah dan dianalisa untuk dijadikan acuan bagi Dinas Pekerjaan Umum (PU) dalam melakukan beberapa kegiatan pembangunan di Kota Bengkulu. Adapaun kriteria/indikator yang digunakan pada analisa tersebut dapat dilihat pada tabel 1 .
Tabel 1. Indikator Analisa

\begin{tabular}{|c|l|}
\hline NO & \multicolumn{1}{|c|}{ INDIKATOR } \\
\hline 1 & Bangunan Hunian Tidak Teratur \\
\hline 2 & Luas Lantai kurang dari 7,2 m2/org \\
\hline & $\begin{array}{l}\text { Rumah tidak layak (sesuai persyaratan } \\
\text { teknis) }\end{array}$ \\
\hline 4 & Jalan lingkungan $\leq 1,5$ meter \\
\hline 5 & Jalan lingkungan $\geq 1,5$ meter yang rusak \\
\hline 6 & $\begin{array}{l}\text { Jalan lingkungan } \geq 1,5 \text { meter yang } \\
\text { tidak diperkeras }\end{array}$ \\
\hline 7 & Jalan $\geq 1,5$ meter tanpa saluran samping \\
\hline 8 & Drainase yang tidak layak \\
\hline 9 & Tidak terlayani sarana air minum \\
\hline 10 & Tidak punya akses jamban/ MCK \\
\hline 11 & Jamban/MCK tidak layak \\
\hline 12 & $\begin{array}{l}\text { Sampah RT tidak terangkut min. 2x } \\
\text { seminggu }\end{array}$ \\
\hline 13 & Bangunan hunian tidak memiliki IMB \\
\hline 14 & $\begin{array}{l}\text { Bangunan hunian tanpa sertifikat/ } \\
\text { HGB/ SKT }\end{array}$ \\
\hline
\end{tabular}

Penelitian ini nantinya akan membantu TIM P2KKP dalam melakukan pengelompokkan daerah. Pengelompokkan tersebut akan menggunakan Algoritma Fuzzy $C$ Means Clustering, dimana setiap RT akan dimasukkan pada cluster kelompok berdasarkan derajat keanggotannya yang dihitung menggunakan 14 kriteria yang sudah ditetapkan.

Setelah itu akan diimplementasikan pula metode Simple Additive Weighting dalam memberikan rekomendasi RT mana saja yang akan mendapatkan bantuan dalam kelompok-kelompok RT yang sudah terbentuk dari hasil clustering. Selain itu pula penelitian ini nantinya dapat membantu TIM P2KKP agar memiliki sebuah database yang berisikan kondisi wilayah permukiman warga kota Bengkulu yang dapat diakses oleh publik. Hal ini sebagai bentuk transparansi data dan hasil analisa dalam pemberian bantuan, sesuai dengan UU No 14 Tahun 2008 tentang Keterbukaan Informasi Publik

B. Rumusan Masalah

1. Bagaimana melakukan pengelompokan Kelurahan/RT se-Kota Bengkulu 
menggunakan algoritma Fuzzy C-Means

Clustering berdasarkan pada 14 kriteria yang sudah ditetapkan. (lihat tabel 1.1)

2. Bagaimana melakukan perangkingan RT berdasarkan 14 kriteria yang sudah ditetapkan (tabel 1.1) dan memberikan rekomendasi pemberian bantuan Program Peningkatan Kualitas Kawasan Permukiman (P2KKP) se-Kota Bengkulu menggunakan algoritma Simple Additive Weighting pada setiap kluster.

3. Bagaimana menyajikan data dan hasil analisa kondisi Wilayah Permukiman yang ada di Kota Bengkulu yang dapat diakses oleh publik.

C. Batasan Masalah

Batasan Masalah yang diberikan dalam penelitian ini adalah :

1. Data yang akan digunakan dalam pehitungan adalah Data Kualitas Kawasan Permukiman pada tingkat RT bersumber pada rekap akhir tahun yang dilakukan oleh TIM P2KKP kota Bengkulu

2. Kriteria yang digunakan dalam perhitungan menggunakan Fuzzy C-Means Clustering dan Simple Additive Weighting adalah kriteria yang sudah ditetapkan oleh TIM P2KKP kota Bengkulu, yaitu sebanyak 14 kriteria dengan 3 Kluster (lihat tabel 1.1).

3. Dalam proses clustering, RT-RT dikelompokkan dalam 3 kluster berdasarkan tingkat kesamaan indikator tanpa memberikan justifikasi kualitas dari klusterkluster tersebut,
D. Tujuan Penelitian

Tujuan yang ingin dicapai dalam penelitian ini antara lain :

1. Melakukan pengelompokkan Kelurahan /RT se-Kota Bengkulu berdasarkan 14 indikator yang telah di tetapkan TIM P2KKP Kota Bengkulu.

2. Memberikan alternatif rekomendasi pemberian bantuan Program Peningkatan Kualitas Kawasan Permukiman di Kota Bengkulu

3. Membuat media publikasi data dan hasil analisa pemberian bantuan kepada masyarakat dalam bentuk website yang dapat diakses secara online.

E. Manfaat Penelitian

Adapun manfaat dari penelitian ini adalah:

1. Penelitian ini dapat menyajikan hasil pengelompokkan (clustering) kelurahan /RT berdasarkan 14 indikator yang telah di tetapkan TIM P2KKP Kota Bengkulu, sehingga dapat diketahui daerah-daerah yang memiliki nilai indikator permukimannya.

2. Penelitian ini dapat memberikan alternatif rekomendasi dalam pemberian bantuan Program Peningkatan Kualitas Kawasan Permukiman di Kota Bengkulu.

3. Penelitian ini dapat menyajikan data dan hasil kondisi wilayah permukiman yang ada di Kota Bengkulu dalam bentuk tabel dan grafik untuk 14 indikator kualitas permukiman yang dapat diakses oleh publik. 
Jurnal Pseudocode, Volume III Nomor 2, September 2016, ISSN 2355-5920

\section{TINJAUAN PUSTAKA}

A. Program Peningkatan Kualitas Kawasan Permukiman (P2KKP)

P2KKP merupakan program pemerintah yang secara substansi berupaya dalam penanggulangan kemiskinan melalui konsep memberdayakan masyarakat dan pelaku pembangunan lokal lainnya, termasuk Pemerintah Daerah dan kelompok peduli setempat [2]. P2KKP dibentuk dengan harapan dapat membangun "gerakan kemandirian penanggulangan kemiskinan dan pembangunan berkelanjutan", yang bertumpu pada nilai-nilai luhur dan prinsip-prinsip universal.

Poin penting P2KKP adalah bagaimana meningkatkan kualitas kawasan permukiman di perkotaan agar dapat mengurangi tingkat kemiskinan yang terjadi di masyarakat. Oleh karena itu P2KKP yang merupakan konsultan dari Dinas Pekerjaan Umum (PU) membuat rekomendasi daerah dengan kondisi wilayah permukiman yang kurang layak, sehingga dapat diprioritaskan untuk diberikan bantuan pembangunan. Adapun beberapa contoh indikator yang biasa digunakan dapat dilihat pada tabel 1 .

\section{B. Fuzzy C-Means Clustering (FCM)}

Saat ini ada beberapa algoritma clustering data, salah satu diantaranya adalah Fuzzy C-Means (FCM). FCM adalah suatu teknik peng-cluster-an data yang mana keberadaan tiap-tiap titik data dalam suatu cluster ditentukan oleh derajat keanggotaannya. Teknik ini pertama kali diperkenalkan oleh Jim Bezdek pada tahun 1981 [3]. Konsep dasar FCM, pertama kali adalah menentukan pusat cluster, yang akan menandai lokasi rata-rata untuk tiap cluster. Pada kondisi awal, pusat cluster ini masih belum akurat. Tiaptiap data memiliki derajat keanggotaan untuk tiaptiap cluster. Dengan cara memperbaiki pusat cluster dan nilai keanggotaaannya tiap-tiap data secara berulang, maka akan dapat dilihat bahwa pusat cluster akan bergerak menuju lokasi yang tepat. Perulangan ini didasarkan pada minimasi fungsi objektif [4].

\section{Simple Additive Weighting (SAW)}

Simple Additive Weighting sering juga dikenal istilah metode penjumlahan terbobot. Konsep dasar metode Simple Additive Weighting adalah mencari penjumlahan terbobot dari rating kinerja pada setiap alternatif pada semua atribut. Metode Simple Additive Weighting membutuhkan proses normalisasi matriks keputusan $(X)$ ke suatu skala yang dapat diperbandingkan dengan semua rating alternatif yang ada [5].

\section{PERANCANGAN SISTEM}

\section{A. Analisis Sistem}

Sistem yang akan dibangun nantinya akan menggunakan Bahasa pemrograman PHP dengan framework Codeigniter dan database Mysql. Sebelum melakukan implementasi, dibutuhkan analisis data dan sistem. Hal ini dilakukan sebagai upaya untuk mempermudah pada tahapan pembuatan sistem nantinya. Untuk data yang digunakan dalam penelitian ini adalah data indikator kondisi permukiman di Kota Bengkulu pada tingkat RT, sebanyak 1.183 RT dengan 14 indikator (tabel 1). Berikut akan dipaparkan diagram alir (flowchart) dari sistem ini pada Gambar 1. 


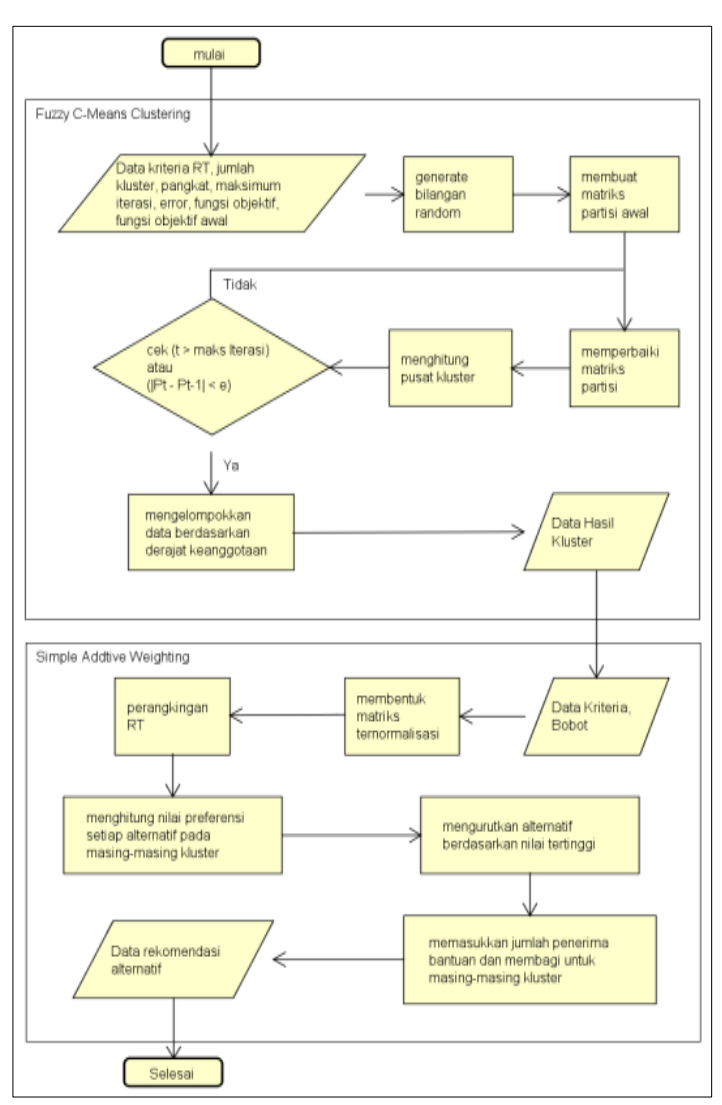

Gambar 1. Diagram Alir (flowchart) Sistem

IV. IMPLEMENTASI

A. Implementasi Antarmuka

Halaman Beranda (Frontend):

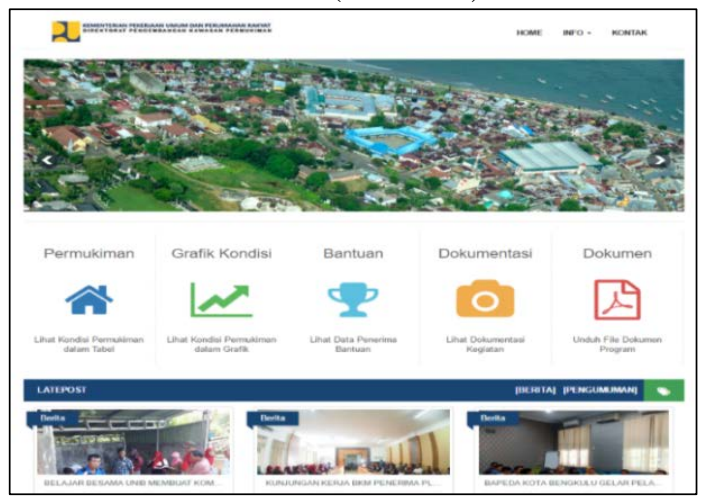

Gambar 2. Implementasi Antarmuka Halaman Beranda

\section{B. Perhitungan Fuzzy C-Means Clustering}

Sebelum melakukan perhitungan menggunakan algoritma fuzzy c-means clustering, pada sistem ini sudah diinputkan terlebih dahulu data-data kriteria (14 indikator) yang biasa digunakan TIM P2KKP dalam memberikan bantuan. Jumlah Data tersebut sebanyak 1.183 (RT) se-Kota Bengkulu. Dalam perhitungan ini akan ditampilkan 10 data sebagai sampel yang menunjukkan proses perhitungan dengan tetap menggunakan nilai akumulasi dari semua data-data yang ada. Berikut adalah perhitungan yang dilakukan :

\section{a. Input Data Kedalam Matriks (Tabel)}

Tabel 2. Nilai Indikator (Kriteria) Perhitungan

\begin{tabular}{|c|c|c|c|c|c|c|c|c|c|c|c|c|c|c|}
\hline No & $\mathbf{J 0 1}$ & $\mathbf{J 0 2}$ & $\mathbf{J 0 3}$ & $\mathbf{J 0 4}$ & $\mathbf{J 0 5}$ & $\mathbf{J 0 6}$ & $\mathbf{J 0 7}$ & $\mathbf{J 0 8}$ & $\mathbf{J 0}$ & $\mathbf{J 1}$ & $\mathbf{J 1}$ & $\mathbf{J 1}$ & $\mathbf{J 1}$ & $\mathbf{J 1}$ \\
\hline 28 & 0 & 2 & 0 & 0 & 0 & 0 & 0 & 0 & 0 & 0 & 4 & 0 & 0 & 0 \\
\hline 157 & 16 & 7 & 0 & 1000 & 1000 & 1500 & 2000 & 240 & 18 & 4 & 1 & 17 & 48 & 0 \\
\hline 202 & 0 & 17 & 0 & 200 & 500 & 500 & 534 & 396 & 0 & 0 & 0 & 72 & 0 & 0 \\
\hline 241 & 10 & 12 & 4 & 110 & 245 & 350 & 330 & 300 & 24 & 0 & 23 & 0 & 31 & 15 \\
\hline 365 & 0 & 8 & 8 & 0 & 0 & 0 & 93 & 40 & 0 & 0 & 0 & 26 & 24 & 0 \\
\hline 478 & 28 & 8 & 3 & 200 & 450 & 500 & 500 & 350 & 6 & 0 & 0 & 0 & 0 & 0 \\
\hline 694 & 15 & 7 & 11 & 250 & 250 & 250 & 450 & 100 & 10 & 0 & 0 & 0 & 33 & 4 \\
\hline 712 & 0 & 8 & 0 & 250 & 415 & 450 & 575 & 580 & 0 & 0 & 0 & 0 & 51 & 2 \\
\hline 912 & 8 & 10 & 0 & 200 & 300 & 500 & 550 & 0 & 40 & 0 & 0 & 37 & 54 & 16 \\
\hline 933 & 0 & 6 & 0 & 0 & 0 & 35 & 0 & 50 & 0 & 0 & 0 & 0 & 4 & 0 \\
\hline
\end{tabular}

Jumlah data yang akan dikluster berjumlah 1.183 data. Dalam proses perhitungan ini hanya digunakan 10 data saja. Data yang digunakan adalah data ke 28, 157, 202, 241, 365, 478, 694, 712, 912 dan 933.

b. Menentukan Nilai Awal

Jumlah cluster $(c)=3$

Jumlah kriteria $(j)=14$

Pangkat $(w)=3$

Maksimum iterasi (MaxIter $)=15$,

Error terkecil yang diharapkan $(\varepsilon)=0.001$, Fungsi objektif awal $(P 0)=0$,

Iterasi awal $($ tawal $)=1$.

c. Membangkitkan Bilangan Random

Dengan menggunakan data sample, dibangkitkan bilangan random yang disimbolkan dengan (ui). 
d. Hitung Pusat Cluster

Tabel 3. Pusat Kluster Iterasi Ke-1 \begin{tabular}{|c|c|c|c|c|c|c|c|c|c|c|c|c|c|}
\hline j01 & j02 & j03 & j04 & j05 & j06 & j07 & j08 & j09 & j10 & j11 & j12 & j13 & j14 \\
\hline
\end{tabular} \begin{tabular}{|c|c|c|c|c|c|c|c|c|c|c|c|c|c|c|}
\hline 7,54 & 6,88 & 3,58 & 172,9 & 314,96 & 501,7 & 559,0 & 383,6 & 14,3 & 1,51 & 4,02 & 21,58 & 29,01 & 6,58 \\
\hline 3,27 & 2,9 & 1,56 & 75,0 & 136,6 & 217,7 & 242,6 & 166, & 6,23 & 0,65 & 1,74 & 9,37 & 12,59 & 2,86 \\
\hline
\end{tabular}

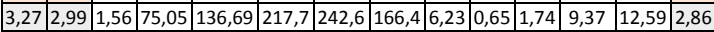

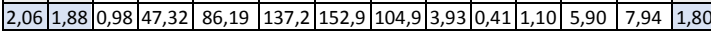

e. Hitung fungsi objektif pada iterasi ke-1

Tabel 4. Perhitungan Fungsi Objektif

\begin{tabular}{|c|c|c|c|c|c|c|c|c|c|c|}
\hline \multirow[b]{2}{*}{ N } & \multicolumn{5}{|c|}{$\left(X_{i j}-V 1 j\right)^{\wedge} \mathbf{2}$} & \multicolumn{5}{|c|}{$(X i j-V 2 j)^{\wedge} 2$} \\
\hline & 1 & 2 & & 14 & $\Sigma$ & 1 & 2 & & 14 & $\Sigma$ \\
\hline 028 & 56,82 & 23,84 & & 43,33 & 842116,81 & 10,70 & 0,97 & & 8,16 & 158623,7 \\
\hline 157 & 71,61 & 0,01 & & 43,33 & 4247548,5 & 162,0 & 16,10 & & 8,16 & 6340475, \\
\hline 202 & 56,82 & 102,36 & & 43,33 & 39578,46 & 10,70 & 196,36 & & 8,16 & 369193,9 \\
\hline 241 & 6,06 & 26,19 & . & 70,86 & 92333,52 & 45,27 & 81,23 & & $\begin{array}{c}147, \\
4\end{array}$ & 57378,60 \\
\hline 365 & 56,82 & 1,25 & . & 43,33 & 716440,12 & 10,70 & 25,13 & & 8,16 & 110649,8 \\
\hline 478 & 418,71 & 1,25 & & 43,33 & 25442,43 & 611,5 & 25,13 & & 8,16 & 294261,0 \\
\hline 694 & 55,69 & 0,01 & & 67 & 166477,20 & 137,5 & 16,10 & & 1,31 & 92683,96 \\
\hline 712 & 56,82 & 1,25 & & 21,00 & 58710,93 & 10,70 & 25,13 & & 0,73 & 445119,0 \\
\hline 912 & 0,21 & 9,72 & & 88,69 & 149853,82 & 22,36 & 49,18 & & $\begin{array}{c}172, \\
7 \\
\end{array}$ & 248025,6 \\
\hline 933 & 56,82 & 0,78 & & 43,33 & 772136,92 & 10,70 & 9,08 & & 8,16 & 130378,4 \\
\hline
\end{tabular}

$$
P_{1}=495.836 .668,496
$$

f. Hitung Perubahan matriks partisi

Tabel 5. Hasil Klustering Iterasi ke 1

\begin{tabular}{|c|l|l|c|c|c|c|}
\hline & $\begin{array}{l}\text { NAMA } \\
\text { RT }\end{array}$ & $\begin{array}{l}\text { NAMA } \\
\text { KELURAHAN }\end{array}$ & $\begin{array}{c}\text { Ui1 } \\
\text { Baru }\end{array}$ & $\begin{array}{c}\text { Ui2 } \\
\text { Baru }\end{array}$ & $\begin{array}{c}\text { Ui3 } \\
\text { Baru }\end{array}$ & K \\
\hline 028 & $\begin{array}{l}\text { RT028- } \\
\text { RW008 }\end{array}$ & $\begin{array}{l}\text { PEKAN } \\
\text { SABTU }\end{array}$ & 0.0004 & 0.0591 & 0.9405 & 3 \\
\hline 157 & $\begin{array}{l}\text { RT043- } \\
\text { RW008 }\end{array}$ & $\begin{array}{l}\text { PAGAR } \\
\text { DEWA }\end{array}$ & 0.6574 & 0.1977 & 0.1449 & 1 \\
\hline 202 & $\begin{array}{l}\text { RT015- } \\
\text { RW003 }\end{array}$ & $\begin{array}{l}\text { SUMUR } \\
\text { DEWA }\end{array}$ & 0.9984 & 0.0012 & 0.0004 & 1 \\
\hline 241 & $\begin{array}{l}\text { RT007- } \\
\text { RW002 }\end{array}$ & $\begin{array}{l}\text { BELAKANG } \\
\text { PONDOK }\end{array}$ & 0.1844 & 0.7685 & 0.0471 & 2 \\
\hline 365 & $\begin{array}{l}\text { RT002- } \\
\text { RW001 }\end{array}$ & PASAR BARU & 0.0001 & 0.0363 & 0.9635 & 3 \\
\hline 478 & $\begin{array}{l}\text { RT007- } \\
\text { RW002 }\end{array}$ & $\begin{array}{l}\text { RAWA } \\
\text { MAKMUR P }\end{array}$ & 0.9992 & 0.0006 & 0.0002 & 1 \\
\hline 694 & $\begin{array}{l}\text { RT007- } \\
\text { RW002 }\end{array}$ & $\begin{array}{l}\text { KEBUN } \\
\text { KENANGA }\end{array}$ & 0.1293 & 0.7491 & 0.1217 & 2 \\
\hline 712 & $\begin{array}{l}\text { RT004- } \\
\text { RW001 }\end{array}$ & $\begin{array}{l}\text { KEBUN } \\
\text { TEBENG }\end{array}$ & 0.997 & 0.0023 & 0.0007 & 1 \\
\hline 912 & $\begin{array}{l}\text { RT007- } \\
\text { RW002 }\end{array}$ & $\begin{array}{l}\text { DUSUN } \\
\text { BESAR }\end{array}$ & 0.7783 & 0.1716 & 0.0501 & 1 \\
\hline 933 & $\begin{array}{l}\text { RT001- } \\
\text { RW001 }\end{array}$ & $\begin{array}{l}\text { JALAN } \\
\text { GEDANG }\end{array}$ & 0.0002 & 0.0438 & 0.956 & 3 \\
\hline
\end{tabular}

g. Cek Kondisi Berhenti :

Proses Perhitungan sudah melewati 13 kali iterasi. Pada kondisi iterasi pertama, derajat keanggotaan data diwakilkan oleh bilangan random, namun pada iterasi-iterasi berikutnya digunakan derajat keanggotaan nilai yang dihitung berdasarkan pusat kluster yang telah diperoleh pada iterasi. Pada iterasi ke 13,
Data 912 (RT007-RW002) Kel. DUSUN

BESAR pindah ke Kluster 2.

C. Perhitungan Simple Addtive Weighting

a. Membuat matriks keputusan $Z$ berukuran $m x n$

Untuk matriks awal ini sama dengan perhitungan yang dilakukan di klustering pada tabel 5.

b. Memberikan nilai bobot preferensi $(W)$

Bobot yang diberikan dalam penelitian ini adalah 1.

c. Melakukan normalisasi matriks keputusan $Z$

Berikut adalah perhitungan nilai normalisasi pada algoritma Simple Additive Weighting (data ke-241)

$$
\begin{array}{l|l|l}
r_{241.1}=\frac{10}{87}=0.11 & r_{241.2}=\frac{12}{77}=0.16 & r_{241.3}=\frac{4}{77}=0.05 \\
r_{241.3}=\frac{4}{77}=0.05 & r_{241.3}=\frac{4}{77}=0.05 & r_{241.3}=\frac{4}{77}=0.05 \\
r_{241.3}=\frac{4}{77}=0.05 & r_{241.3}=\frac{4}{77}=0.05 & r_{241.3}=\frac{4}{77}=0.05 \\
r_{241.3}=\frac{4}{77}=0.05 & r_{241.3}=\frac{4}{77}=0.05 & r_{241.3}=\frac{4}{77}=0.05 \\
r_{241.13}=\frac{31}{127}=0.24 & r_{241.14}=\frac{15}{118}=0.13 &
\end{array}
$$

d. Melakukan Perangkingan dan Perhitungan nilai Preferensi

Detail perhitungan, data ke 241 sebagai berikut :

$$
\begin{aligned}
\mathrm{V} 241=1(0.11)+ & 1(0.16)+1(0.05)+1(0.24) \\
& +1(0.52)+1(0.41) \\
& +1(0.37)+1(0.15) \\
& +1(0.20)+1(0.00) \\
& +1(0.22)+1(0.24) \\
& +1(0.13)=2.793
\end{aligned}
$$

Nilai rangking suatu data ditentukan dengan nilai preferensinya. Nilai preferensi ini akan diurutkan dan dibandingkan pada data-data 
lainnya dalam kluster yang sama, sehingga akan didapatkan rangking-rangking RT yang layak mendapatkan bantuan untuk masingmasing klusternya

Berikut ditampilkan tabel 6. beberapa RT penerima bantuan berdasarkan nilai rangking tertinggi :

Tabel. 6. Daftar RT Penerima Bantuan

\begin{tabular}{|c|c|c|c|c|c|}
\hline $\mathbf{R}$ & NO & $\begin{array}{c}\text { NAMA } \\
\text { RT }\end{array}$ & $\begin{array}{c}\text { NAMA } \\
\text { KELURAHAN }\end{array}$ & $\mathbf{K}$ & $\begin{array}{c}\text { NILAI } \\
\text { RANG- } \\
\text { KING }\end{array}$ \\
\hline 1 & 569 & $\begin{array}{l}\text { RT013- } \\
\text { RW004 }\end{array}$ & $\begin{array}{l}\text { TELUK } \\
\text { SEPANG }\end{array}$ & 1 & 5,457 \\
\hline 2 & 581 & $\begin{array}{l}\text { RT011- } \\
\text { RW002 }\end{array}$ & $\begin{array}{l}\text { SUMBER } \\
\text { JAYA }\end{array}$ & 2 & 5,405 \\
\hline 3 & 309 & $\begin{array}{l}\text { RT006- } \\
\text { RW002 }\end{array}$ & $\begin{array}{l}\text { PONDOK } \\
\text { BESI }\end{array}$ & 2 & 5,138 \\
\hline 4 & 607 & $\begin{array}{l}\text { RT011- } \\
\text { RW003 }\end{array}$ & $\begin{array}{l}\text { KANDANG } \\
\text { MAS }\end{array}$ & 1 & 5,055 \\
\hline 5 & 613 & $\begin{array}{l}\text { RT017- } \\
\text { RW005 }\end{array}$ & $\begin{array}{l}\text { KANDANG } \\
\text { MAS }\end{array}$ & 1 & 5,048 \\
\hline 6 & 579 & $\begin{array}{l}\text { RT009- } \\
\text { RW002 }\end{array}$ & $\begin{array}{l}\text { SUMBER } \\
\text { JAYA }\end{array}$ & 2 & 4,864 \\
\hline 7 & 580 & $\begin{array}{l}\text { RT010- } \\
\text { RW002 }\end{array}$ & $\begin{array}{l}\text { SUMBER } \\
\text { JAYA }\end{array}$ & 2 & 4,761 \\
\hline 8 & 391 & $\begin{array}{l}\text { RT002- } \\
\text { RW004 }\end{array}$ & BENTIRING & 2 & 4,659 \\
\hline 9 & 830 & $\begin{array}{l}\text { RT003- } \\
\text { RW001 }\end{array}$ & PASAR BKL & 3 & 3,925 \\
\hline$:$ & & $:$ & : & $:$ & $:$ \\
\hline 14 & 582 & $\begin{array}{l}\text { RT012- } \\
\text { RW002 }\end{array}$ & $\begin{array}{l}\text { SUMBER } \\
\text { JAYA }\end{array}$ & 3 & 3,741 \\
\hline$:$ & & : & : & : & $:$ \\
\hline 100 & 959 & $\begin{array}{l}\text { RT005- } \\
\text { RW002 } \\
\end{array}$ & $\begin{array}{l}\text { JEMBATAN } \\
\text { KECIL }\end{array}$ & 3 & 1,435 \\
\hline
\end{tabular}

\section{KESIMPULAN DAN SARAN}

A. Kesimpulan

1. Sistem ini telah berhasil melakukan proses pengelompokkan RT se-Kota Bengkulu kedalam 3 kluster menggunakan algoritma fuzzy c-means clustering.

2. Sistem ini juga telah berhasil melakukan proses perangkingan RT se-Kota Bengkulu algoritma simple additive weighting dan memberikan rekomendasi berupa daftar RT-RT yang layak menerima bantuan dengan nilai rangking tertinggi.
3. Sistem ini sudah dapat dijadikan media publikasi informasi TIM P2KKP Kota Bengkulu kepada masyarakat.

B. Saran

1. Penelitian selanjutnya disarankan menggunakan metode klustering lainnya seperti k-means.

2. Untuk penerapan sistem secara nyata, penulis menyarankan untuk menggunakan algoritma simple additive weighting saja, tanpa dilakukan proses klustering.

\section{REFERENSI}

[1] PU-net. (2016, February 01). Retrieved from KPUPR Website: http://www.pu.go.id/.

[2] P2kp.org. (2016, Februari 21). Retrieved from Website P2KKP: http://www.p2kp.org/.

[3] Kusumadewi, S., \& Purnomo, H. (2010). “Aplikasi Logika Fuzzy untuk Pendukung Keputusan”. Yogyakarta: Graha Ilmu

[4] Kusumadewi, S., \& Hartati, S. (2010). "Neuro-Fuzzy Integrasi Sistem Fuzzy \& Jaringan Syaraf Edisi 2”. Yogyakarta: Graha Ilmu Ilmu.

[5] Pujatama, D. (2014). “Implementasi Algoritma Simple Additive Weighting untuk mendukung keputusan penerimaan beasiswa PPA pada Universitas Dian Nuswantoro”. Semarang: Universitas Dian Nuswantoro. 